\title{
Danos em pós-colheita de goiabas na Região do Centro-Oeste Paulista
}

\author{
Ivan Herman Fischer $\left({ }^{1 *}\right)$; Aparecida Marques de Almeida ( $\left.{ }^{1}\right)$; Maria Cecília de Arruda ( $\left.{ }^{1}\right)$; \\ Rosemary Marques de Almeida Bertani ('); Maria José de Marchi Garcia ('); Lilian Amorim ( ${ }^{2}$ ) \\ (') Agência Paulista de Tecnologia dos Agronegócios (APTA), Polo Centro-Oeste, Av. Rodrigues Alves, 40-40, 17030-000 Bauru (SP). \\ (2) ESALQ-USP, Departamento de Fitopatologia, Caixa Postal 9, 13418-900 Piracicaba (SP). \\ (*) Autor correspondente: ihfische@apta.sp.gov.br
}

Recebido: 3/jun./2010; Aceito: 3/nov./2010.

\section{Resumo}

As doenças pós-colheita representam sério obstáculo à cultura da goiaba, uma vez que comprometem a qualidade e a quantidade dos frutos para comercialização. Neste estudo, foram identificadas e quantificadas injúrias mecânicas decorrentes dos processos de colheita e transporte das goiabas. Além disso, avaliou-se a incidência de doenças pós-colheita e pragas em goiabas da cultivar 'Pedro Sato' comercializadas na CEASA-Bauru e em goiabas das cultivares 'Pedro Sato' e 'Paluma' de pomares do Centro-Oeste paulista. Os frutos de goiaba amostrados em quatro etapas da colheita (colheita com luva, sacola do colhedor, contentor e barracão) e na CEASA foram armazenados durante nove dias a $25^{\circ} \mathrm{C}$. A incidência de injúrias foi avaliada visualmente a cada três dias. A ocorrência de frutos com podridões foi superior na goiaba 'Pedro Sato' ( $92,0 \%$ a 96,6\%) comparada a 'Paluma' (77,1\%) no fim do armazenamento. A antracnose foi a principal doença nas duas cultivares, seguida pela pinta-preta. A incidência de injúrias mecânicas foi crescente no decorrer das etapas de colheita, entretanto, não influenciaram no aparecimento das podridões. Elevada infestação de moscas-das-frutas foi constatada na goiaba 'Paluma'.

Palavras-chave: Colletotrichum spp., doenças pós-colheita, Guignardia psidii, Psidium guajava.

\section{Postharvest damages in guavas from the Midwest region of the State of São Paulo}

\begin{abstract}
Postharvest diseases represent a serious drawback to guava crop, once they reduce quality and quantity of fruits for marketing. This study identified and quantified mechanical injuries resulting from the processes of harvesting and transporting of guavas and the incidence of postharvest diseases and pests in 'Pedro Sato' guava commercialized at CEASA/Bauru and in 'Pedro Sato' and 'Paluma' guavas cultivated in the Midwest Region of the State of São Paulo. Guava fruit collected at four harvest stages (harvest with gloves, harvest bag, tractor trailer and packing table) and at a wholesale market (CEASA) were stored for nine days at $25^{\circ} \mathrm{C}$. The incidence of damages was visually evaluated every three days. The occurrence of rot fruit was higher in Pedro Sato cultivar (92.0\% to 96.6\%) than in 'Paluma' $(77.1 \%)$ at the end of storage period. Anthracnose was the main disease in the two cultivars, followed for the black spot. The incidence of mechanical injuries increased along the harvest stages; however, it was not related to the occurrence of rots. High infestation of fruit fly in 'Paluma' guava was also verified.
\end{abstract}

Key words: Colletotrichum spp., Guignardia psidii, postharvest diseases, Psidium guajava.

\section{INTRODUÇÃO}

O Estado de São Paulo é responsável por 32,6\% da produção brasileira de goiaba (Psidium guajava L.), comercializando 102.965 toneladas produzidas em 4.236 hectares em 2007 (FNP, 2010). A produção se concentra em três grandes regióes que compreendem os municípios de Valinhos, Taquaritinga e Mirandópolis e seus circunvizinhos (Francisco et al., 2005).

As injúrias mecânicas causadas por impacto, compressão e corte, e as podridóes são comumente obser- vadas após a colheita de frutos e de hortaliças, sendo responsáveis pela redução da qualidade e, consequentemente, desvalorizaçáo comercial dos produtos (CHItarra e Chitarra, 2005). As injúrias mecânicas, além de alterar a aparência dos frutos, estimulam a produção de etileno, acelerando o amadurecimento e reduzindo a vida útil (KLuge et al., 2002). Goiabas das cultivares 'Paluma' e 'Pedro Sato' submetidas a impacto, compressão ou corte tiveram escurecimento na área injuriada do fruto, culminando com uma irregularidade no amadurecimento (MatTiuz e Durigan, 2001). 
As doenças pós-colheita caracterizam-se inicialmente por manchas necróticas que afetam a parte externa e interna do fruto e podem ser separadas em duas categorias baseadas na infecção pelo patógeno. Infecções típicas são ocasionadas por patógenos que infectam os frutos após a colheita e latente quando a infecção ocorre em frutos imaturos antes da colheita (BARKAI-Golan, 2001). As infecçôes latentes permanecem até a maturação, quando ocorrem mudanças estruturais e fisiológicas que desencadeiam o surgimento dos sintomas da doença (BARKAIGolan, 2001). As principais doenças pós-colheita em goiaba, como a antracnose, causada por Colletotrichum gloeosporioides Penz e C. acutatum Simmonds; a pinta preta, causada por Guignardia psidii Ullasa \& Rawal [anamorfo: Phyllosticta psidiicola (Petrak)] e a podridão de Fusicoccum sp., pertencem à categoria de doenças quiescentes, embora patógenos em pós-colheita típicos como os dos gêneros Aspergillus, Fusarium, Pestalotiopsis e Rhizopus, também podem ocorrer (BARKAI-Golan, 2001; Martins et al., 2007).

Os ferimentos são fundamentais para a infecção de patógenos que causam doenças típicas em póscolheita, assim como favorecem a penetração dos patógenos quiescentes que possuem a capacidade de penetrar nos frutos de forma direta (Piccinin et al., 2005). Dessa forma, qualquer medida que reduza a incidência de ferimentos deve ter impacto na incidência das doenças pós-colheita. Os ferimentos podem ser ocasionados no momento da colheita, decorrentes do manuseio inapropriado do fruto pelo colhedor e uso de materiais de colheita inadequados, ou após a colheita, durante o transporte e manipulação em "packinghouses" e mercados consumidores. A caracterização de injúrias mecânicas e de suas causas pode ser, portanto, fundamental para que o manejo das doenças pós-colheita seja otimizado.

Estimativas de danos (redução na qualidade ou quantidade de um produto) pós-colheita em frutíferas variam de $10 \%$ a 50\% (Benato et al., 2001, Амоrim et al., 2008; Fischer et al., 2008), em funçấo do produto, da região produtora e da tecnologia empregada na produçáo. No Entreposto Terminal de São Paulo (ETSP) da CEAGESP, em $63 \%$ das goiabas comercializadas nas safras de 2005 e 2006 houve incidência de injúrias mecânicas e em 5,5\% dos frutos ocorreram sintomas de doenças pós-colheita (Martins et al., 2007). No entanto, essa estimativa foi feita em um único ponto da cadeia produtiva (mercado atacadista), sendo razoável inferir que, ao considerar a totalidade da cadeia produtiva, essas porcentagens sejam ainda maiores.

Neste estudo foram identificadas e quantificadas as injúrias mecânicas bem como sua relação com os danos pós-colheita de origem biótica em goiabas comercializadas na CEASA-Bauru e em pomares do Centro-Oeste paulista.

\section{MATERIAL E MÉTODOS}

\section{Danos pós-colheita em goiabas da Ceasa- Bauru}

Foram realizadas oito amostragens quinzenais de goiabas da cultivar 'Pedro Sato', entre 9/2007 e 12/2007, em permissionários da Ceasa-Bauru. Cada amostragem foi representada por uma caixa de goiaba contendo, em média, 60 frutos, embalados a granel em caixa de madeira, calibre 5-6 (Hortibrasil, 2007) e com > 85\% dos frutos tendo cor da casca verde-clara, correspondente ao estádio de maturação 2 e ângulo de cor ( ${ }^{\circ}$ ) entre 116 e 113, determinado em colorímetro Minolta modelo CR-400 (Azzolini et al., 2004). As goiabas foram procedentes de Monte Alto (seis caixas de seis pomares diferentes) e Taquaritinga, SP (duas caixas de um pomar).

As caixas de goiaba foram transportadas até o laboratório onde 50 frutos no estádio de maturação 2 foram selecionados, identificados, acondicionados individualmente em bandejas plásticas. Em seguida, as bandejas foram transferidas para câmara úmida feita com saco plástico e algodáo úmido, por 24 horas, para favorecer o aparecimento de estruturas de possíveis patógenos presentes no material coletado. Em seguida, os frutos foram armazenados a $25^{\circ} \mathrm{C}$ e $60 \pm 5 \%$ de umidade relativa em ambiente de laboratório. As avaliaçóes dos danos foram realizadas após a retirada da câmara úmida e aos 3, 6 e 9 dias de armazenamento.

Sintomas visuais mensuráveis causados por agentes biológicos nocivos ou impactos mecânicos foram denominados injúria; dano constituiu-se na reduçáo em quantidade e/ou qualidade do fruto e perda a reduçáo financeira decorrente do dano, segundo ZADOCKs (1985). No entanto, em doenças pós-colheita que afetam todo o fruto, os termos injúria e dano muitas vezes são sinônimos, pois a incidência de injúria coincide com a redução em qualidade ou quantidade comercializada. Assim, o termo dano foi adotado, preferencialmente, sempre que essa generalizaçáo náo comprometesse seu significado.

A diagnose das injúrias mecânicas, caracterizadas, segundo Hortibrasil (2007), em batida (escurecimento da casca do fruto decorrente de impacto mecânico); prensado (decorrente principalmente da compressão do fruto com a caixa de madeira); injúria cicatrizada (tecido suberizado decorrente principalmente do ataque de pragas e do atrito dos frutos com as folhas); injúria não cicatrizada (caracterizada pela ruptura da epiderme do fruto com exposição da polpa) e a diagnose das doenças e das pragas foram feitas em função dos sintomas visuais e da análise dos sinais dos patógenos em microscópio de luz (BARNETT e Hunter, 1998). Os patógenos fúngicos tiveram a patogenicidade confirmada através da inserção de discos de micélio em quatro frutos sadios, previamente desinfesta- 
dos superficialmente com hipoclorito de sódio $(0,5 \%)$ e feridos, segundo metodologia de NerY-Silva et al. (2007). Diagnosticada a etiologia do agente causal da podridão, o fruto foi descartado. Frutos com sintomas de ataque de moscas-das-frutas foram desconsiderados na quantificação de doenças pós-colheita, pois eram imprestáveis para o consumo. O modelo monomolecular $\left(y=1-\left(1-y_{0}\right) \exp (r t)\right.$ no qual $y=$ incidência das doenças, em proporção, $y_{0}=$ incidência inicial, $r=$ taxa de incremento e $t=$ tempo, foi ajustado às curvas de progresso das incidências de antracnose, pinta preta e podridão de Fusicoccum em função do tempo de armazenamento por meio de regressão não linear com auxílio do programa Statistica v.6 (Tulsa, EUA). As incidências iniciais e as taxas de progresso das curvas de cada doença foram comparadas por meio do test-t também utilizando o programa Statistica v.6.

Compararam-se as incidências das podridôes em goiabas da cultivar 'Pedro Sato' por meio de teste não paramétrico de comparação de múltiplas proporçóes ao nível de 5\% de probabilidade (ZAR, 1999). Sempre que significativo, as proporçôes foram comparadas após as seguintes transformaçóes: $\left[\mathrm{Pi}=\mathrm{X} /(\mathrm{n}+1), \mathrm{Pi}^{\prime}=(\mathrm{X}+1) /(\mathrm{n}+1)\right.$, e $\left.\mathrm{Pi}^{\prime \prime}=1 / 2\left(\operatorname{asen} \sqrt{\mathrm{Pi}}+\operatorname{asen} \sqrt{ } \mathrm{Pi}^{\prime}\right)\right]$, onde: $\mathrm{X}=$ número de frutos totais de cada proporção; $\mathrm{n}=$ número de frutos doentes de cada proporção e Pi" = Proporção transformada, de acordo com ZAR (1999).

\section{Danos pós-colheita em goiabas de pomares do Centro-Oeste paulista}

Levantamentos mensais das injúrias mecânicas e de origem biótica pós-colheita foram realizados durante a safra de goiaba 9/2007 a 2/2008, em seis propriedades, sendo três com goiabas da cultivar 'Pedro Sato' (Brotas, Itaju e Monte Alto, SP) e três da cultivar 'Paluma' (Taquaritinga, Ibirá e Cafelândia, SP), da Região Centro-Oeste paulista que produzem frutos destinados para indústria e, eventualmente, para o mercado de fruto fresco.

Cinquenta frutos no estádio de maturação 2, correspondente à cor da casca verde-clara $(\mathrm{oh}=116-113)$ (Azzolini et al., 2004) foram coletados em três etapas sequenciais da colheita: i) colhedor - os frutos foram coletados diretamente da sacola de pano que fica junto ao corpo do colhedor no momento da colheita; ii) contentor - coletados das caixas sobre a carreta do trator ainda no campo e iii) barracão - coletados do balcão de seleção da casa de embalagem localizada próximo à área de produção. Adicionalmente, foi realizada uma coleta ideal feita sempre pela mesma pessoa, cujos frutos foram cuidadosamente colhidos com o uso de luva cirúrgica. Os frutos amostrados nas três etapas e na coleta ideal foram imediatamente acondicionados em caixas plásticas com células individuais e transportados ao laboratório, totalizando 200 frutos por propriedade.
Os frutos foram armazenados a $25^{\circ} \mathrm{C}$ e $60 \pm 5 \%$ de umidade relativa e as avaliaçóes dos danos foram realizadas após a retirada da câmara úmida e aos 3, 6 e 9 dias de armazenamento, seguindo o mesmo método utilizado nos frutos da Ceasa. Compararam-se as incidências das doenças pós-colheita entre as cultivares e entre as etapas de colheita para cada cultivar aos nove dias de armazenamento, por meio de teste não paramétrico de comparação de múltiplas proporções ao nível de $5 \%$ de probabilidade (ZAR, 1999). A incidência de injúrias mecânicas pós-colheita nas diferentes etapas de colheita foi correlacionada com a incidência de podridóes utilizando-se a correlação de Spearman $(\mathrm{p}<0,05)$.

\section{RESULTADOS}

\section{Danos pós-colheita em goiabas comercializadas na Ceasa-Bauru}

Nos frutos de goiaba da cultivar 'Pedro Sato' ocorreu incidência de diferentes doenças fúngicas pós-colheita, atingindo o total médio de 3,1\%; 38,5\%; $80,4 \%$ e $92,0 \%$, aos $1,3,6$ e 9 dias de armazenamento respectivamente (Tabela 1). O modelo monomolecular ajustou-se às curvas de progresso da antracnose $\left(y_{\mathrm{o}}=0, r=\right.$ $\left.0,17, \mathrm{R}^{2}=0,98\right)$ e da podridão de Fusicoccum sp. $\left(y_{\mathrm{o}}=\right.$ $\left.0, r=0,006, \mathrm{R}^{2}=0,93\right)$ e mostrou taxa de progresso significativamente maior $(\mathrm{p}<0,05)$ para a antracnose. Não houve ajuste significativo para a curva de progresso da pinta preta. A antracnose foi de maior incidência dentre as podridóes detectadas nos frutos, diferindo significativamente das demais doenças a partir do terceiro dia pós-colheita. A pinta preta atingiu a segunda maior incidência, sendo estatisticamente semelhante às podridōes de Fusicoccum sp., Phoma psidii, Mucor hiemalis e Aspergillus niger durante o armazenamento (Tabela 1). Outras doenças constatadas em menor incidência foram as podridões causadas por Pestalotiopsis psidii, Phomopsis spp., Dothiorella spp. e Rhizopus stolonifer.

A incidência média de injúrias mecânicas foi elevada em goiabas da cultivar 'Pedro Sato', em que $77,5 \%$ dos frutos tiveram sintomas de injúria não cicatrizada; 75,0\% batida, $9,5 \%$ prensado e $6,3 \%$ dano no pedúnculo, caracterizado por uma injúria não cicatrizada originária na operação de colheita. A incidência de injúria não cicatrizada e batida foi superior a $50 \%$ nas oito amostras. A incidência de injúria cicatrizada foi de $17,5 \%$ e de frutos considerados imaturos em 2,8\%. Foram ainda observados, em menor incidência $(<2,0 \%)$, frutos deformados, rachados, passados e com umbigo malformado.

A incidência média de moscas-das-frutas em goiabas da cultivar 'Pedro Sato' foi de 2,5\%. Sintomas do ataque de tripes, percevejo e cochonilha foram verificados em níveis próximos de $1,0 \%$. 
Tabela 1. Incidência (\%) de doenças pós-colheita em frutos de goiaba da cultivar 'Pedro Sato' comercializados na CEASA-Bauru, entre setembro e dezembro de 2007 durante nove dias de armazenamento ${ }^{(1)}$

\begin{tabular}{|c|c|c|c|c|}
\hline \multirow{2}{*}{ Doenças } & \multicolumn{4}{|c|}{ Dias de armazenamento $\left({ }^{2}\right)$} \\
\hline & 1 & 3 & 6 & 9 \\
\hline Antracnose (Colletotrichum spp.) & $2,8 \mathrm{~A}$ & $32,5 \mathrm{~A}$ & $64,0 \mathrm{~A}$ & $71,5 \mathrm{~A}$ \\
\hline Pinta preta (Guignardia psidii) & $0,0 \mathrm{~B}$ & $2,3 \mathrm{~B}$ & $4,5 \mathrm{~B}$ & $4,8 \mathrm{~B}$ \\
\hline Podridão de Fusicoccum sp. & $0,0 \mathrm{~B}$ & $0,3 \mathrm{BC}$ & $3,5 \mathrm{BC}$ & $4,5 \mathrm{~B}$ \\
\hline Podridão de Phoma psidii & $0,0 \mathrm{~B}$ & $0,3 \mathrm{BC}$ & $2,8 \mathrm{BCD}$ & $4,0 \mathrm{~B}$ \\
\hline Podridão de Phomopsis spp. & $0,0 \mathrm{~B}$ & $0,0 \mathrm{C}$ & $1,5 \mathrm{BCDE}$ & $2,3 \mathrm{BC}$ \\
\hline Podridão de Pestalotiopsis psidii & $0,0 \mathrm{~B}$ & $0,0 \mathrm{C}$ & $1,0 \mathrm{CDE}$ & $1,5 \mathrm{BC}$ \\
\hline Podridão de Mucor hiemalis & $0,3 \mathrm{AB}$ & $1,3 \mathrm{BC}$ & 1,3 BCDE & $1,3 \mathrm{BC}$ \\
\hline Podridão de Aspergillus niger & $0,0 \mathrm{~B}$ & $1,3 \mathrm{BC}$ & $1,3 \mathrm{BCDE}$ & $1,3 \mathrm{BC}$ \\
\hline Podridão de Rhizopus stolonifer & $0,0 \mathrm{~B}$ & $0,5 \mathrm{BC}$ & $0,5 \mathrm{DE}$ & $0,5 \mathrm{C}$ \\
\hline Podridão de Dothiorella spp. & $0,0 \mathrm{~B}$ & $0,0 \mathrm{C}$ & $0,0 \mathrm{E}$ & $0,3 \mathrm{C}$ \\
\hline Total & 3,1 & 38,5 & 80,4 & 92,0 \\
\hline
\end{tabular}

(1) Média de oito amostragens de 50 frutos cada uma.

$\left(^{2}\right)$ Valores seguidos pela mesma letra maiúscula na coluna náo diferem entre si ao nível de $5 \%$ de probabilidade pelo teste não paramétrico de comparaçáo de múltiplas proporçóes.

\section{Danos pós-colheita em goiabas de pomares do Centro-Oeste paulista}

Os frutos de goiabas das cultivares 'Pedro Sato' e 'Paluma' tiveram incidência de diferentes doenças fúngicas pós-colheita, atingindo o total médio de $42,8 \%$ e $25,0 \%$ aos três dias de armazenamento e $96,6 \%$ e $77,1 \%$ aos nove dias de armazenamento (Tabela 2) respectivamente. Nos frutos de goiaba da cultivar 'Pedro Sato' a incidência média foi significativamente maior $(\mathrm{p}<0,05)$ de podridóes em relação à cultivar Paluma, com destaque para a antracnose e podridôes causadas por Phoma psidii, Pestalotiopsis psidii e Phomopsis spp. (Tabela 2).

Dentre as podridóes detectadas nas duas cultivares de goiabas, a antracnose propiciou as maiores incidências médias (35,5\%-46,2\%), diferindo significativamente das demais doenças em frutos de goiaba da cultivar 'Pedro Sato'. A pinta preta foi a segunda maior incidência, estatisticamente semelhante à antracnose em frutos de goiaba da cultivar 'Paluma', seguida, pelas podridôes causadas por Fusicoccum sp., Phoma psidii, Pestalotiopsis psidii, Phomopsis spp. e $M$. hiemalis. Outras doenças também constatadas em menor incidência $(<1,0 \%)$, nas cultivares de goiaba, foram as podridóes causadas por $R$. stolonifer, Dothiorella spp., A. niger e Lasiodiplodia theobromae (Tabela 2).

A incidência de podridóes nas goiabas náo diferiu estatisticamente nas diferentes etapas de colheita nos períodos avaliados, com valores médios para 'Pedro Sato' entre 96,1\% no contentor/barracão e $97,3 \%$ na coleta ideal. Para 'Paluma' entre $70,1 \%$ na colheita ideal e $87,7 \%$ no contentor aos nove dias de armazenamento respectivamente (Tabela 3).

As injúrias não cicatrizadas e batidas foram crescentes com as etapas de colheita, com incidências no barracão para os frutos de goiaba da cultivar 'Pedro Sato' de 76,0\% e $69,3 \%$ e para a cultivar 'Paluma' de $86,0 \%$ e $35,3 \%$ respectivamente (Figura 1). A maior incidência $(\mathrm{p}<0,05)$ de lesóes não cicatrizadas foi observada para os frutos da cultivar 'Pedro Sato'. A incidência de lesôes cicatrizadas foi semelhante nas duas cultivares, com média de $16,1 \%$, e assim como as injúrias no pedúnculo não diferiu estatisticamente entre as etapas de colheita. Foram ainda observados, em menor incidência ( $<2 \%$ ), frutos deformados, rachados, passados e com umbigo mal formado.

Não foi observada correlação significativa $(\mathrm{p}<0,05)$ da incidência de injúrias mecânicas com a incidência de podridóes em goiabas cultivares 'Pedro Sato' $(r=-0,14)$ e 'Paluma' $(r=0,21)$, e com as principais doenças, antracnose $(\mathrm{r}=0,28$ e 0,42$)$ e pinta preta $(\mathrm{r}=-0,28$ e 0,37$)$, para as duas cultivares, respectivamente, nas etapas de colheita.

A incidência de moscas-das-frutas foi de $43,2 \%$ e $3,0 \%$ nos frutos de goiabas das cultivares 'Paluma' e 'Pedro Sato' respectivamente. Sintomas de tripes foram de $27,3 \%$ e $36,2 \%$, respectivamente, nos frutos das cultivares 'Pedro Sato' e 'Paluma'. Foram ainda observados sintomas de ataque de gafanhoto $(9,0 \%)$, gorgulho $(7,2 \%) \mathrm{e}$ percevejo $(3,7 \%)$ nos frutos da cultivar 'Paluma'.

\section{DISCUSSÃO}

Os resultados com goiabas obtidas da Ceasa-Bauru e dos pomares do Centro-Oeste paulista foram equiparáveis e mostram elevada incidência de podridóes pós-colheita, indicando necessidade de mudanças no manejo dessas doenças. As podridóes pós-colheita desqualificam o fruto para comercialização e não devem ultrapassar $20 \%$ durante a vida útil dos frutos (PAulL, 1999), embora incidências de até $40 \%$ de doenças pós-colheita em goiabas já 
Tabela 2. Incidência (\%) de doenças pós-colheita em frutos de goiaba das cultivares 'Pedro Sato' e 'Paluma' provenientes de pomares do Centro-Oeste paulista, no período 9/2007 a 2/2008 aos três e nove dias de armazenamento ${ }^{(1)}$

\begin{tabular}{|c|c|c|c|c|}
\hline \multirow{2}{*}{ Doenças } & Pedro Sato & Paluma & Pedro Sato & Paluma \\
\hline & \multicolumn{2}{|c|}{3 dias $^{(2)}$} & \multicolumn{2}{|c|}{9 dias ${ }^{(2)}$} \\
\hline Antracnose (Colletotrichum spp.) & 21,3 aA & $14,5 \mathrm{bA}$ & 46,2 aA & 35,5 bA \\
\hline Pinta preta (Guignardia psidii) & $12,5 \mathrm{aB}$ & 7,5 bB & $25,5 \mathrm{aB}$ & 30,3 aA \\
\hline Podridão de Fusicoccum sp. & $1,8 \mathrm{aC}$ & $1,2 \mathrm{aC}$ & $5,2 \mathrm{aCD}$ & $8,0 \mathrm{aB}$ \\
\hline Podridão de Phoma psidii & $2,2 \mathrm{aC}$ & $0,5 \mathrm{bC}$ & $8,2 \mathrm{aC}$ & $1,3 \mathrm{bBC}$ \\
\hline Podridão de Pestalotiopsis psidii & $2,0 \mathrm{aC}$ & $0,3 \mathrm{bc}$ & $5,8 \mathrm{aCD}$ & $0,8 \mathrm{bBC}$ \\
\hline Podridão de Phomopsis spp. & $0,7 \mathrm{aC}$ & $0,3 \mathrm{aC}$ & $2,7 \mathrm{aCD}$ & $0,3 \mathrm{bc}$ \\
\hline Podridão de Mucor hiemalis & $1,2 \mathrm{aC}$ & $0,3 \mathrm{aC}$ & $1,5 \mathrm{aCD}$ & $0,3 \mathrm{aC}$ \\
\hline Podridão de Rhizopus stolonifer & $0,5 \mathrm{aC}$ & $0,0 \mathrm{aC}$ & $0,8 \mathrm{aD}$ & $0,0 \mathrm{aC}$ \\
\hline Podridão de Dothiorella spp. & $0,2 \mathrm{aC}$ & $0,2 \mathrm{aC}$ & $0,2 \mathrm{aD}$ & $0,3 \mathrm{aC}$ \\
\hline Podridão de Aspergillus niger & $0,2 \mathrm{aC}$ & $0,2 \mathrm{aC}$ & $0,3 \mathrm{aD}$ & $0,3 \mathrm{aC}$ \\
\hline Podr. Lasiodiplodia theobromae & $0,2 \mathrm{aC}$ & $0,0 \mathrm{aC}$ & $0,2 \mathrm{aD}$ & $0,0 \mathrm{aC}$ \\
\hline Total & $42,8 \mathrm{a}$ & $25,0 \mathrm{~b}$ & 96,6 a & $77,1 \mathrm{~b}$ \\
\hline
\end{tabular}

(1) Média de três amostragens de 200 frutos para as duas cultivares de goiaba.

${ }^{(2)}$ Valores seguidos pela mesma letra, minúscula na linha para cada período de armazenamento e maiúscula na coluna, nấo diferem entre si ao nível de $5 \%$ pelo teste nấo paramétrico de comparaçăo de múltiplas proporçóes.

Tabela 3. Incidência (\%) de doenças pós-colheita em frutos de goiaba das cultivares 'Pedro Sato' e 'Paluma' provenientes de diferentes etapas de colheita em pomares do Centro-Oeste paulista aos nove dias de armazenamento ${ }^{(1)}$

\begin{tabular}{|c|c|c|c|c|c|c|c|c|}
\hline \multirow[b]{2}{*}{ Doenças } & \multicolumn{4}{|c|}{ Pedro Sato (2) } & \multicolumn{4}{|c|}{ Paluma ${ }^{(2)}$} \\
\hline & $\begin{array}{c}\text { Colheita } \\
\text { ideal }\end{array}$ & Colhedor & Contentor & Barracão & $\begin{array}{l}\text { Colheita } \\
\text { ideal }\end{array}$ & Colhedor & Contentor & Barracão \\
\hline Antracnose (Colletotrichum spp.) & $49,3 \mathrm{a}$ & $50,7 \mathrm{a}$ & $40,0 \mathrm{a}$ & $44,7 \mathrm{a}$ & $32,0 \mathrm{a}$ & 32,7 a & $39,3 \mathrm{a}$ & $38,0 \mathrm{a}$ \\
\hline Pinta preta (Guignardia psidii) & $22,7 \mathrm{a}$ & $23,3 \mathrm{a}$ & $28,7 \mathrm{a}$ & $27,3 \mathrm{a}$ & $26,7 \mathrm{a}$ & $29,3 \mathrm{a}$ & $34,7 \mathrm{a}$ & 30,7 a \\
\hline Podridão de Pestalotiopsis psidii & $5,3 \mathrm{a}$ & $7,3 \mathrm{a}$ & $7,3 \mathrm{a}$ & $3,3 \mathrm{a}$ & $0,0 \mathrm{a}$ & $2,0 \mathrm{a}$ & $0,7 \mathrm{a}$ & $0,7 \mathrm{a}$ \\
\hline Podridão de Rhizopus stolonifer & $0,0 \mathrm{a}$ & $0,0 \mathrm{a}$ & $2,7 \mathrm{a}$ & $0,7 \mathrm{a}$ & $0,0 \mathrm{a}$ & $0,0 \mathrm{a}$ & $0,0 \mathrm{a}$ & $0,0 \mathrm{a}$ \\
\hline Podridão de Fusicoccum sp. & $5,3 \mathrm{a}$ & $4,7 \mathrm{a}$ & $4,0 \mathrm{a}$ & $6,7 \mathrm{a}$ & $10,0 \mathrm{a}$ & $5,7 \mathrm{a}$ & $11,0 \mathrm{a}$ & $5,3 \mathrm{a}$ \\
\hline Podridão de Dothiorella spp. & $0,7 \mathrm{a}$ & $0,0 \mathrm{a}$ & $0,0 \mathrm{a}$ & $0,0 \mathrm{a}$ & $0,0 \mathrm{a}$ & $1,3 \mathrm{a}$ & $0,0 \mathrm{a}$ & $0,0 \mathrm{a}$ \\
\hline Podridão de Phoma psidii & $7,3 \mathrm{a}$ & $4,7 \mathrm{a}$ & $8,7 \mathrm{a}$ & $12,0 \mathrm{a}$ & $0,7 \mathrm{a}$ & $1,3 \mathrm{a}$ & $2,0 \mathrm{a}$ & $1,3 \mathrm{a}$ \\
\hline Podridão de Mucor hiemalis & $2,7 \mathrm{a}$ & $2,0 \mathrm{a}$ & $0,7 \mathrm{a}$ & $0,7 \mathrm{a}$ & $0,7 \mathrm{a}$ & $0,0 \mathrm{a}$ & $0,0 \mathrm{a}$ & $0,7 \mathrm{a}$ \\
\hline Podridão de Phomopsis spp. & $4,0 \mathrm{a}$ & $3,3 \mathrm{a}$ & $3,3 \mathrm{a}$ & $0,0 \mathrm{a}$ & $0,0 \mathrm{a}$ & $1,3 \mathrm{a}$ & $0,0 \mathrm{a}$ & $0,0 \mathrm{a}$ \\
\hline Podr. Lasiodiplodia theobromae & $0,0 \mathrm{a}$ & $0,7 \mathrm{a}$ & $0,0 \mathrm{a}$ & $0,0 \mathrm{a}$ & $0,0 \mathrm{a}$ & $0,0 \mathrm{a}$ & $0,0 \mathrm{a}$ & $0,0 \mathrm{a}$ \\
\hline Podridão de Aspergillus niger & $0,0 \mathrm{a}$ & $0,0 \mathrm{a}$ & $0,7 \mathrm{a}$ & $0,7 \mathrm{a}$ & $0,0 \mathrm{a}$ & $0,7 \mathrm{a}$ & $0,0 \mathrm{a}$ & $0,7 \mathrm{a}$ \\
\hline Total & $97,3 \mathrm{a}$ & $96,7 \mathrm{a}$ & $96,1 \mathrm{a}$ & $96,1 \mathrm{a}$ & $70,1 \mathrm{a}$ & $74,3 \mathrm{a}$ & $87,7 \mathrm{a}$ & $77,4 \mathrm{a}$ \\
\hline
\end{tabular}

(') Média de três amostragens de 50 frutos para as duas cultivares de goiaba

(2) Valores seguidos pela mesma letra minúscula na linha năo diferem entre si para cada cultivar de goiaba ao nível de $5 \%$ pelo teste năo paramétrico de comparaçăo de múltiplas proporçóes.

tenham sido reportadas em outras situaçóes no Estado de São Paulo (Basseto et al., 2002; Martins et al., 2007).

O estádio de maturação em que a goiaba é colhida determina a qualidade a ser oferecida ao consumidor (AzzoLINI et al., 2004). Os frutos foram colhidos no estádio 2, quando havia resistência ao transporte e boas características para o consumo (CAvaline et al., 2006). Segundo Azzolini et al. (2004), frutos colhidos imaturos, além de baixa qualidade, têm alto índice de perda de água e são muito suscetíveis às alteraçôes fisiológicas, enquanto frutos colhidos muito maduros entram rapidamente em senescência. Goiabas da cultivar 'Pedro Sato' colhidas no estádio de maturaçấo 1 (cor da casca verde-escura) tiveram período de comercialização de seis dias, enquanto os frutos colhidos nos estádios 2 e 3 (cor da casca verde-amarela) este período reduzido para, respectivamente, quatro e dois dias, devido, sobretudo à ocorrência de podridôes (Azzolini et al.; 2004). Neste trabalho, o período de comercialização foi ainda menor, pois em frutos colhidos no estádio 2 de maturação os sintomas de podridôes em níveis superiores chegaram a $20 \%$ já no terceiro dia de armazenamento. Segundo Martins et al. (2007), a ele- 
— Lesão não cicatrizada

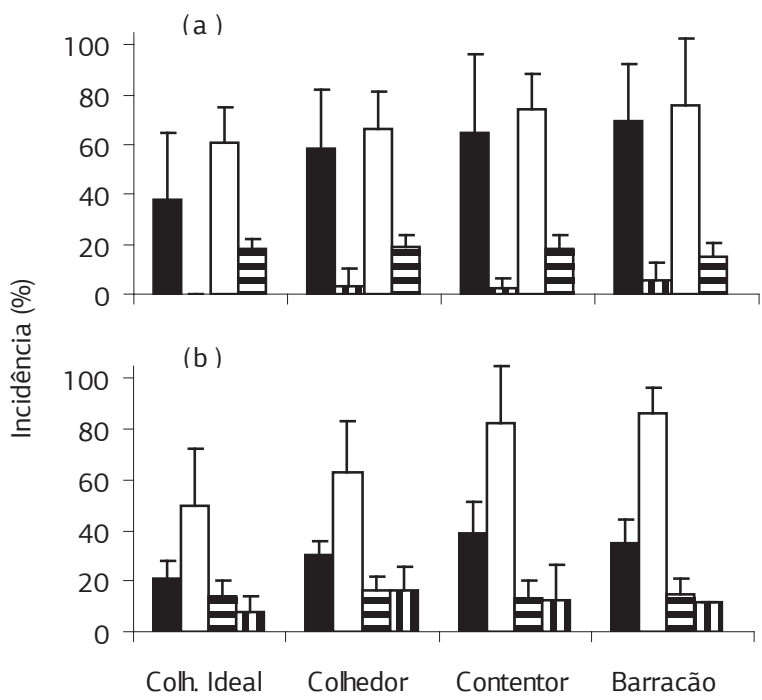

Figura 1. Incidência (\%) de injúrias mecânicas pós-colheita em frutos de goiaba das cultivares 'Pedro Sato' (a) e 'Paluma' (b), provenientes de diferentes etapas de colheita em pomares do Centro-Oeste paulista. Cada símbolo representa a média de três amostras de 50 frutos. As barras representam o desvio-padrão.

vada incidência de podridóes no verão de cada ano é uma das causas para que a colheita dos frutos seja feita antes do ponto de maturaçáo, com consequências negativas na qualidade final do produto, o que sugere a necessidade do emprego de medidas de controle mais efetivas durante as fases de produção e pós-colheita dos frutos.

Neste levantamento verificou-se que a doença pós-colheita mais frequente foi a antracnose, corroborando com relatos na literatura (Piccinin et al., 2005; Rozwalka et al., 2008), seguida pela pinta preta. Entretanto, em goiabas produzidas na regiáo de Campinas, SP e comercializadas na Ceagesp-SP, a pinta preta foi a doença de maior incidência (Martins et al., 2007). Em Taiwan, a incidência de pinta preta em goiabas foi detectada na faixa de $80,2 \%$ a 94,5\% nas cultivares 'Pearl' e 'Crystal' respectivamente, com maiores incidências aos cinco dias após a colheita (Lin et al. 2003). Para o controle dessas doenças, preconizam-se pulverizaçôes preventivas com defensivos agrícolas na fase de pré-colheita (Piccinin et al., 2005).

A ocorrência de injúrias mecânicas provocadas no decorrer da colheita de goiabas não foi acompanhada por um aumento na incidência de podridóes, posto que os principais patógenos encontrados caracterizam-se pela infecção quiescente no campo. É, portanto, impossível prever a incidência destas doenças conhecendo-se a incidência de injúrias póscolheita em goiaba. Ausência de correlação entre injúrias mecânicas e podridóes já havia sido observada por MARTINs et al. (2007) em goiabas não ensacadas comercializadas na Ceagesp. Em contrapartida, correlaçáo positiva foi consta- tada nas goiabas ensacadas (MARTINs et al., 2007), atribuída possivelmente a maior suscetibilidade do fruto ensacado ao dano mecânico por ter casca mais fina em relação ao fruto não ensacado. Correlação positiva entre injúrias mecânicas e incidência da doença bolor verde em citros, causada por $P e-$ nicillium digitatum que penetra no fruto exclusivamente por ferimentos, foi variável em função da variedade cítrica, positiva para laranja 'Pera' e tangor 'Murcott' e ausência de correlação para laranjas 'Lima' e 'Natal', durante beneficiamento em "packinghouse" citrícola (FIscher et al., 2007). Fatores como a densidade de inóculo, manejo fitossanitário, nutrição da planta, estado fisiológico do fruto e a interação destes fatores com a temperatura e umidade relativa podem influenciar a incidência de uma doença em determinada época do ano (Majumdar e Pathak, 1989). Diferenças na incidência de podridôes em função da época e amostras de goiabas foram verificadas por Martins et al. (2007).

A menor incidência da injúria mecânica não cicatrizada nos frutos de goiaba da cultivar 'Paluma' em relaçáo à cultivar 'Pedro Sato' se deve provavelmente às características físicas dos frutos da primeira cultivar que possuem o pericarpo mais espesso, proporcionando maior firmeza e epiderme mais lisa que confere menor resistência ao atrito (Mattiuz e Durigan, 2001).

A elevada incidência de moscas-das-frutas, principal praga da goiabeira (GAllo et al., 2002), nos frutos de goiaba da cultivar 'Paluma' poderia ser minimizada com a técnica do ensacamento dos frutos na árvore com embalagens de papel (FAORO, 2003). Outra técnica seria a aplicação de inseticidas na forma de iscas tóxicas ou em pulverizaçóes. Entretanto, segundo Martins et al. (2007), a técnica do ensacamento dos frutos promove acréscimo significativo na incidência de doenças quiescentes em goiabas, possivelmente relacionado com microclima favorável ao processo infeccioso.

\section{CONCLUSÃO}

A elevada incidência de doenças em pós-colheita, especialmente a antracnose e a infestaçáo por moscas-das-frutas em frutos de goiaba da cultivar 'Paluma', constitui-se nas principais causas de danos pós-colheita.

As injúrias mecânicas oriundas do manuseio dos frutos na colheita e pós-colheita não influenciaram a incidência de doenças pós-colheita nos frutos de goiaba das cultivares 'Paluma' e 'Pedro Sato'.

\section{REFERÊNCIAS}

AMORIM, L.; MARTINS, M.C.; LOURENÇO, S.A.; GUTIERREZ, A.S.D.; ABREU, F.M.; GONÇALVES, F.P. Stone fruit injuries and damage at the wholesale market of São Paulo. Postharvest Biology and Technology, v.47, p.353-357, 2008. 
AZZOLINI, M.; JACOMINO, A.P.; BRON, I.U. Índices para avaliar qualidade pós-colheita de goiabas em diferentes estádios de maturação. Pesquisa Agropecuária Brasileira, v.39, p.139-145, 2004.

BARKAI-GOLAN, R. Postharvest diseases of fruits and vegetables: development and control. Amsterdam: Elsevier, 2001. 418p.

BARNETT, H.L.; HUNTER, B.B. Illustrated Genera of Imperfect Fungi. 4.ed. Saint Paul: American Phytopathological Society, 1998. 218p.

BASSETTO, E.; SESSO, T.; JACOMINO, A.P.; KLUGE, R.A. Efeito de 1-MCP e prochloraz na conservação de goiabas 'Pedro Sato'. Revista Iberoamericana de Tecnologia Postcosecha, v.4, p.122-127, 2002.

BENATO, E.A.; CIA, P.; SOUZA, N.L. Manejo de doenças de frutas pós-colheita. Revisão Anual de Patologia de Plantas, v.9, p.403-440, 2001.

CAVALINI, F.C.; JACOMINO, A.P.; LOCHOSKI, M.A.; KLUGE, R.A.; ORTEGA, E.M.M. Maturity indexes for Kumagai and Paluma guavas. Revista Brasileira de Fruticultura, v.28, p.176$179,2006$.

CHITARRA, M.I,F.; CHITARRA, A.B. Pós-colheita de frutas e hortaliças: fisiologia e manuseio. 2.ed. Lavras: Editora UFLA, 2005. 785p.

FAORO, I.D. Técnica e custo para ensacamento de frutos de pêra japonesa. Revista Brasileira de Fruticultura, v.25, p.339-340, 2003.

FISCHER, I.H.; TOFFANO, L.; LOURENÇO, S.A.; AMORIM, L. Caracterização dos danos pós-colheita em citros procedentes de "packinghouse". Tropical Plant Pathology, v.32, p.304-310, 2007.

FISCHER, I.H.; LOURENÇO, S.A.; AMORIM, L. Doenças póscolheita em citros e caracterização da população fúngica ambiental no mercado atacadista de São Paulo. Tropical Plant Pathology, v.33, p.219-226, 2008.

FNP CONSULTORIA E COMÉRCIO. Agrianual 2010: Agrianual 2010. Anuário estatístico da agricultura brasileira - Goiaba. São Paulo, 2010. p.341-344.

FRANCISCO, V.L.F.S.; BAPTISTELLA, C.S.L.; AMARO, A.A. A cultura da goiaba em São Paulo. Março de 2005. Disponível em <www.iea.sp.gov.br/out/verTexto.php?codTexto=1902> Acesso em: $9 / 9 / 2010$.

GALLO, D.; NAKANO, O.; SILVEIRA NETO, S.; CARVALHO, R.P.L.; BATISTA, G.C.; BERTI FILHO, E.; PARRA, J.R.P.; ZUCCHI, R.A.; ALVES, S.B.; VENDRAMIM, J.D.; MARCHINI,
L.C.; LOPES, J.R.S.; OMOTO, C. Entomologia agrícola. Piracicaba: FEALQ, 2002. 920p.

HORTIBRASIL. Norma de classificação de goiaba. Disponível em <http:/www. hortibrasil.org.br/classificacao/banana/banana. html>. Acesso: 10/9/2010.

KLUGE, R.A.; NACHTIGAL, J.C.; FACHINELLO, J.C.; BILHALVA, A.B. Fisiologia e manejo pós-colheita de frutas de clima temperado. Campinas: Livraria e Editora Rural, 2002. 214p.

LIN, C.C.; LAI, C.S.; TSAI, S.F. Ecological survey of guava new fruit rot - Phyllosticta rot (black spot) and other fruit rots. Plant Protection Bulletin, v.45, p.263-270, 2003.

MAJUMDAR, V.L.; PATHAK, V.N, Incidence of major post-harvest diseases of guava fruits in Jaipur markets. Indian Phytopathology, v.42, p.469-469, 1989.

MARTINS, M.C.; AMORIM, L., LOURENÇO, S.A.; GUTIERREZ, A.S.D.; WATANABE, H.S. Incidência de danos pós-colheita em goiabas no mercado atacadista de São Paulo e sua relação com a prática de ensacamento dos frutos. Revista Brasileira de Fruticultura, v.29, p.245-248, 2007.

MATTIUZ, B.H.; DURIGAN, J.F. Efeito de injúrias mecânicas na firmeza e coloraçáo de goiabas das cultivares Paluma e Pedro Sato. Revista Brasileira de Fruticultura, v.23, p.277-281, 2001.

NERY-SILVA, F.A.; MACHADO, J.C.; RESENDE, M.L.V.; LIMA, L.C.O. Metodologia de inoculação de fungos causadores da podridão peduncular em mamão. Ciência e Agrotecnologia, v.31, p.1374-1379, 2007.

PAULL, R.E. Effects of temperature and relative humidity on fresh commodity quality. Postharvest Biology and Technology, v.15, p.263-277, 1999.

PICCININ, E.; PASCHOLATI, S.F.; DI PIERO, R.M. Doenças da goiabeira. In: KIMATI, H.; AMORIM, L.; REZENDE, J.A.M.; BERGAMIN FILHO, A.; CAMARGO, L.E.A. (Ed.). Manual de fitopatologia: Doenças das plantas cultivadas. 4. ed. São Paulo: Ceres, 2005. v.2, cap.44. p.401-405.

ROZWALKA, L.C.; LIMA, M.L.R.Z.C.; MIO, L.M.M.; NAKASHIMA, T. Extratos, decoctos e óleos essenciais de plantas medicinais e aromáticas na inibição de Glomerela cingulata e Colletotrichum gloeosporioides de frutos de goiaba. Ciência Rural, v.38, p.301-307, 2008.

ZADOKS, J.C. On the conceptual basis of crop loss assessment: the threshold theory. Annual Review of Phytopathology, v.23, p.455-473, 1985 .

ZAR, J.H. Biostatistical analysis. New Jersey: Prentice-Hall, 1999. 663p. 